\title{
Coordination of stomata and vein patterns with leaf width underpins water use efficiency in a $\mathrm{C} 4 \mathrm{crop}$
}

\author{
Ling Pan ${ }^{1}$, Barbara George-Jaeggli ${ }^{2}$, Andrew Borrell ${ }^{2}$, David Jordan ${ }^{2}$, Fiona Koller ${ }^{1}$, Yazen \\ Al-Salman ${ }^{1}$, Oula Ghannoum ${ }^{1}$, and Francisco $\mathrm{Cano}^{3}$ \\ ${ }^{1}$ Western Sydney University Hawkesbury Institute for the Environment \\ ${ }^{2}$ The University of Queensland \\ ${ }^{3}$ Instituto Nacional de Investigación y Tecnología Agraria y Alimentaria
}

May 4, 2021

\begin{abstract}
Despite its importance for crop productivity in drought-affected environments, the underlying mechanisms of variation in intrinsic water use efficiency (iWUE) are not well understood, especially in C4 plants. Recently, Cano et al. (2019) discovered that leaf width (LW) correlated negatively with iWUE and positively with stomatal conductance for water vapour (gsw) across several C4 grasses. Here, we analysed these relationships within 48 field-grown genotypes that cover a broad range of variation in LW in Sorghum bicolor, a well-adapted C4 crop to xeric and hot conditions, by measuring and modelling leaf gas exchange and leaf energy balance three times a day, using anatomical traits as potential drivers for iWUE. LW correlated negatively with iWUE and stomatal density, but positively with gsw, interveinal distance of longitudinal veins (IVDL) and the percentage of stomatal aperture relative to maximum. Energy balance modelling showed that wider leaves opened the stomata more to generate a more negative leaf-to-air temperature difference especially at midday, when air temperatures exceeded $40^{\circ} \mathrm{C}$. These results highlight the important role that LW plays in shaping iWUE through modification of vein and stomatal traits and by regulating stomatal aperture. Therefore, LW could be used as a predictor for higher iWUE among sorghum genotypes.
\end{abstract}

\section{Hosted file}

Ling et al. 2021. R1_no track change.pdf available at https://authorea.com/users/411707/ articles/520644-coordination-of-stomata-and-vein-patterns-with-leaf-width-underpinswater-use-efficiency-in-a-c4-crop 

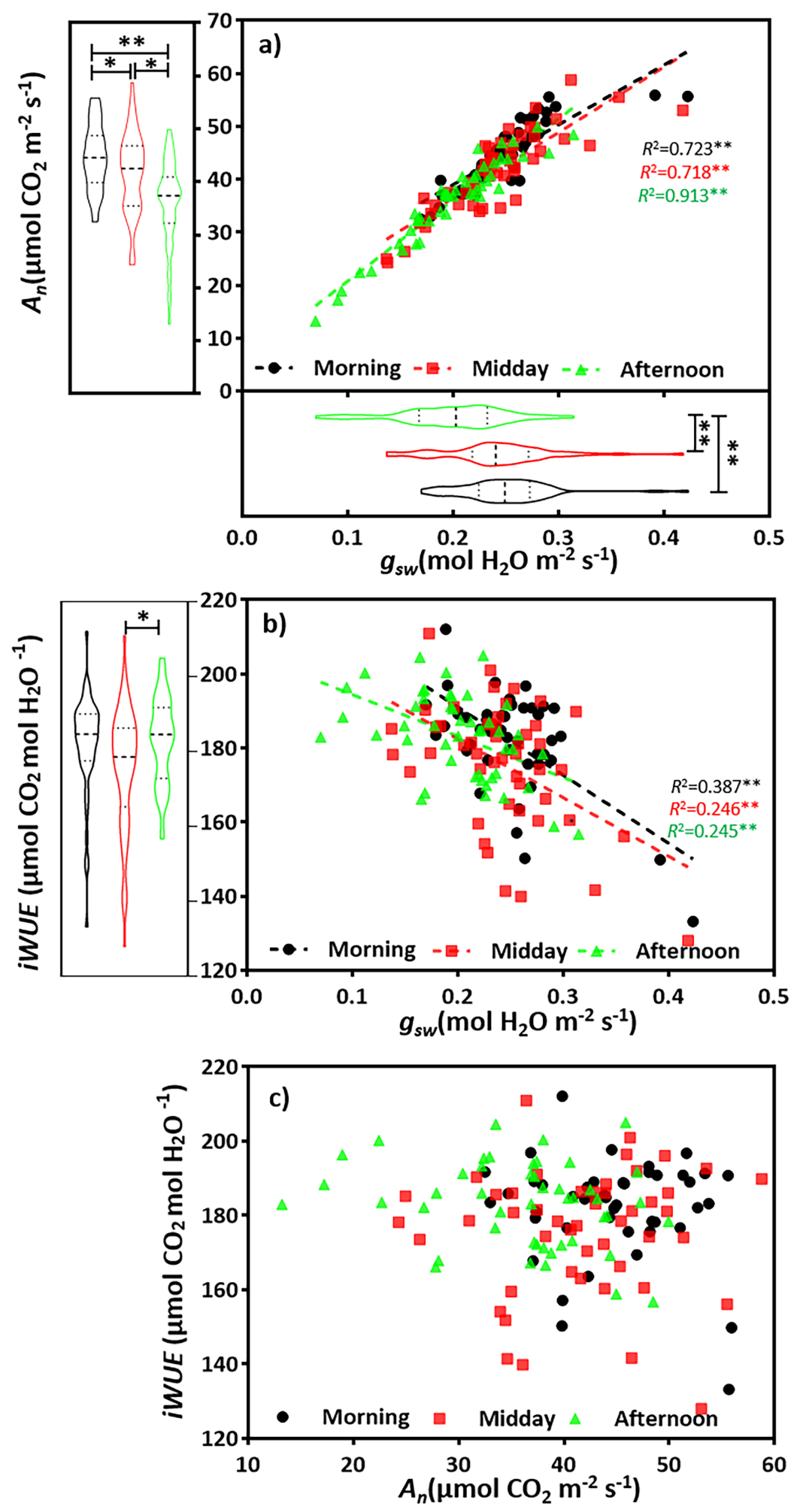

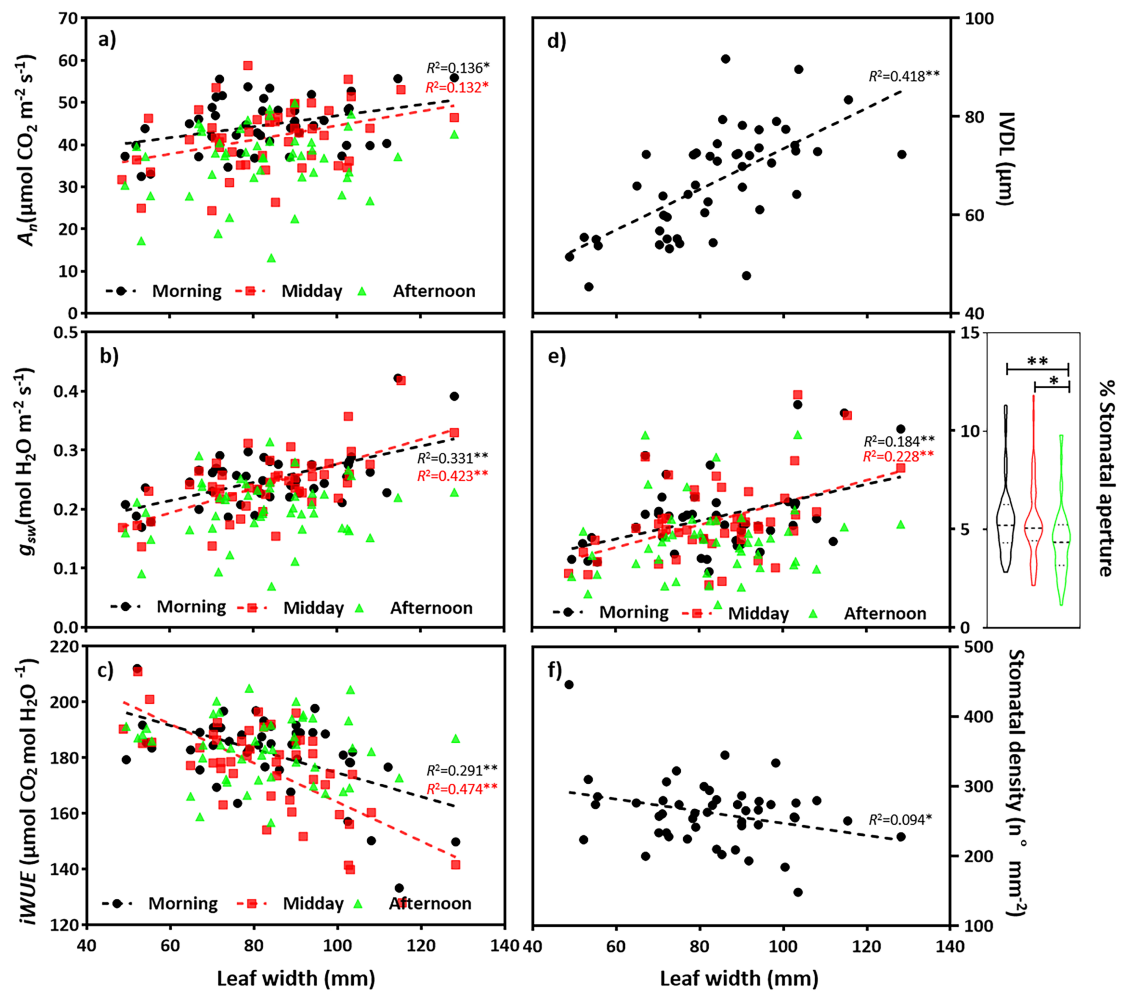

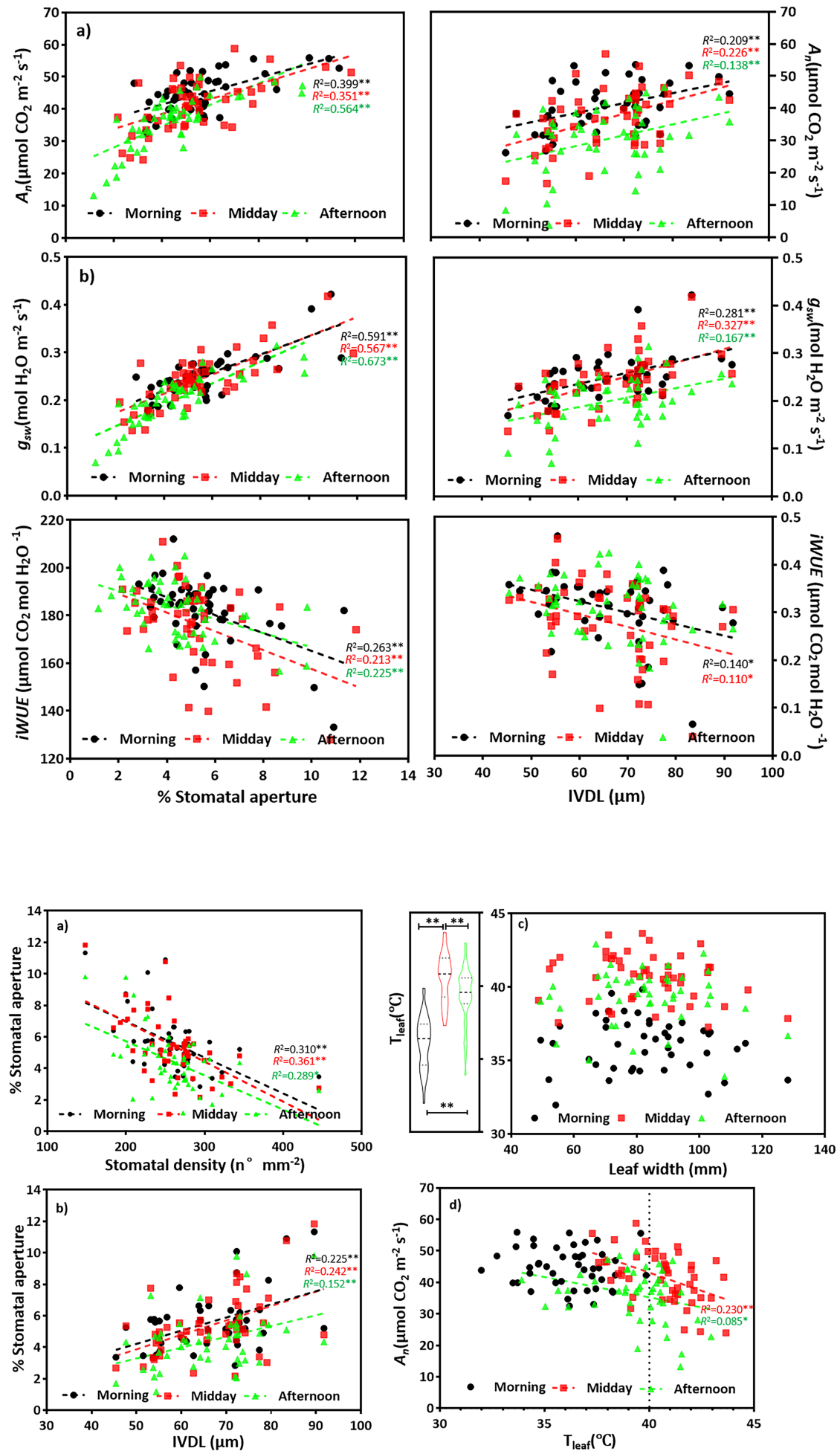

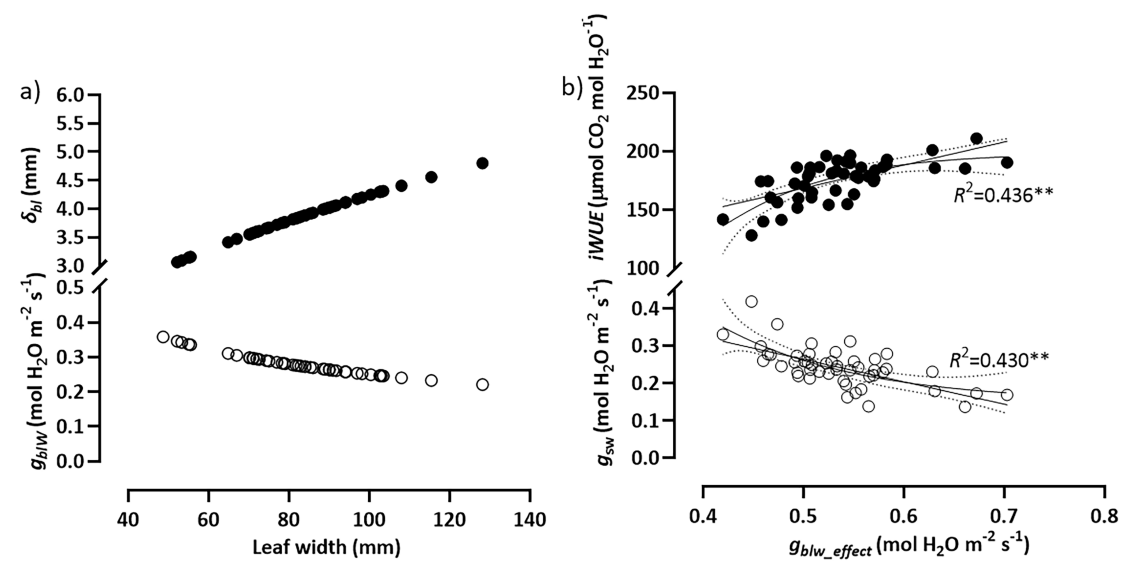


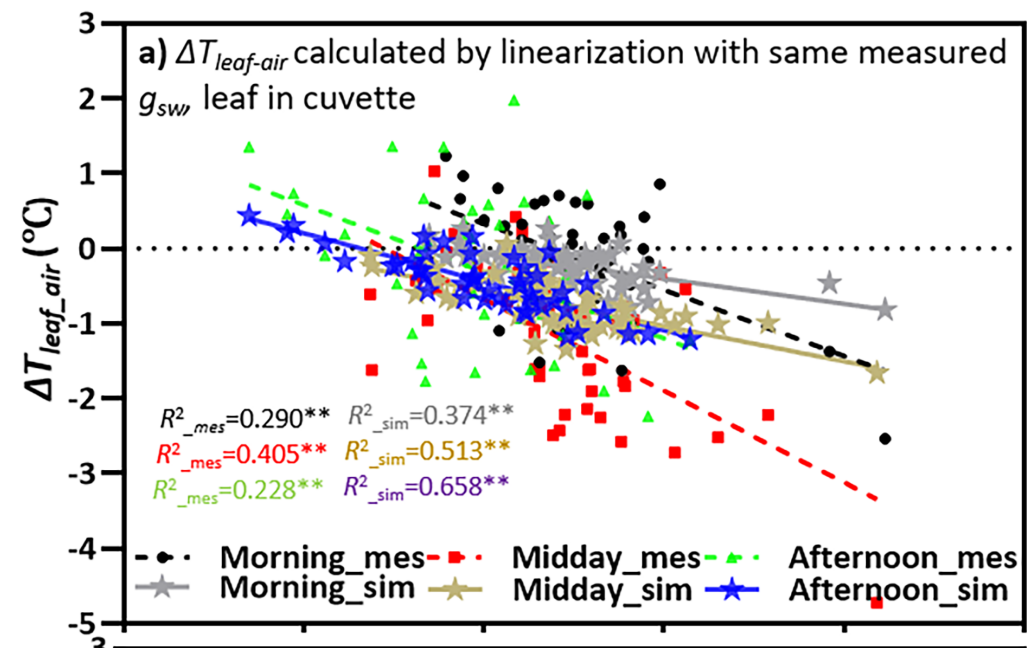

b) $T_{\text {leaf }}$ and $g_{s w}$ modelled by energy balance, leaf in cuvette
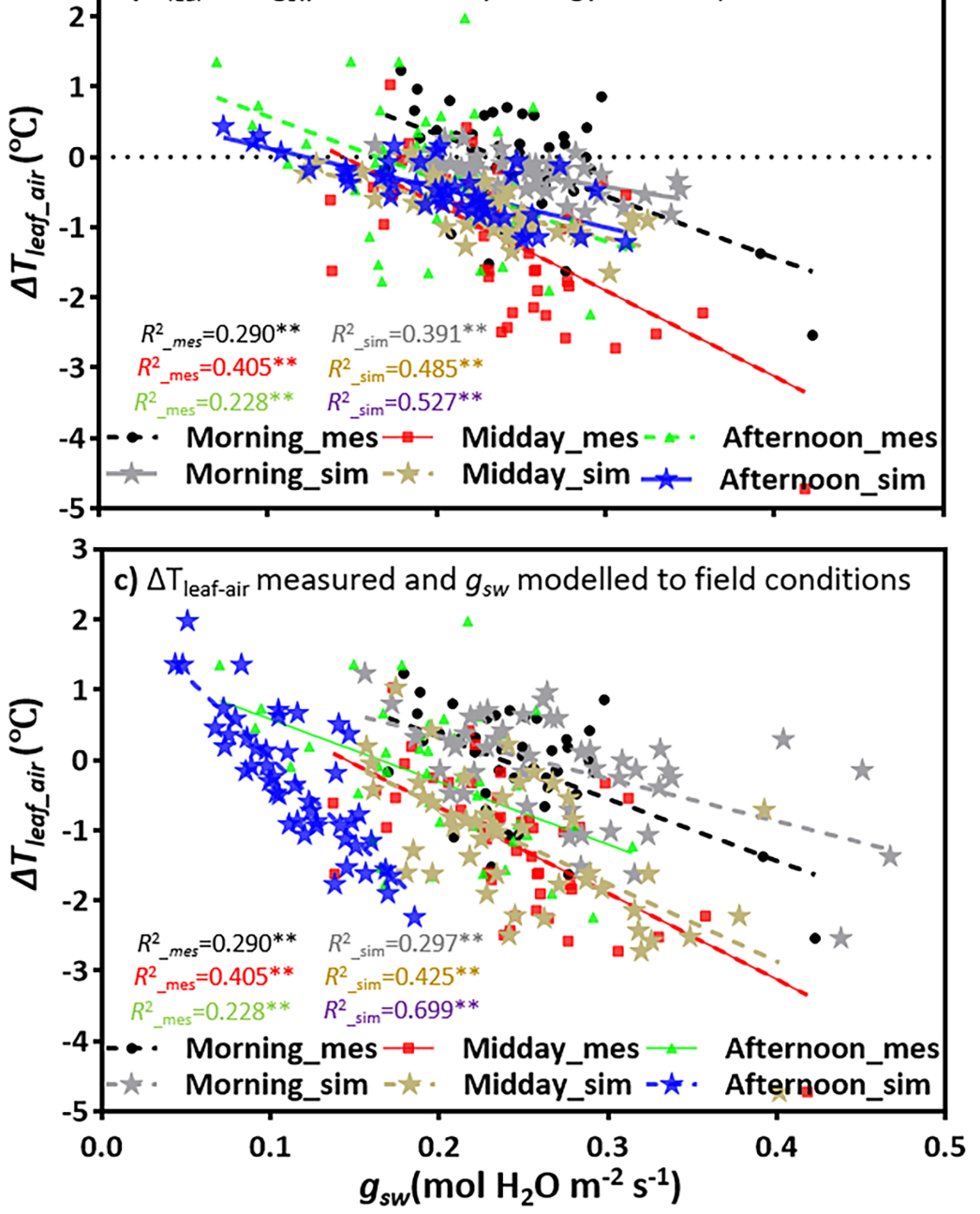

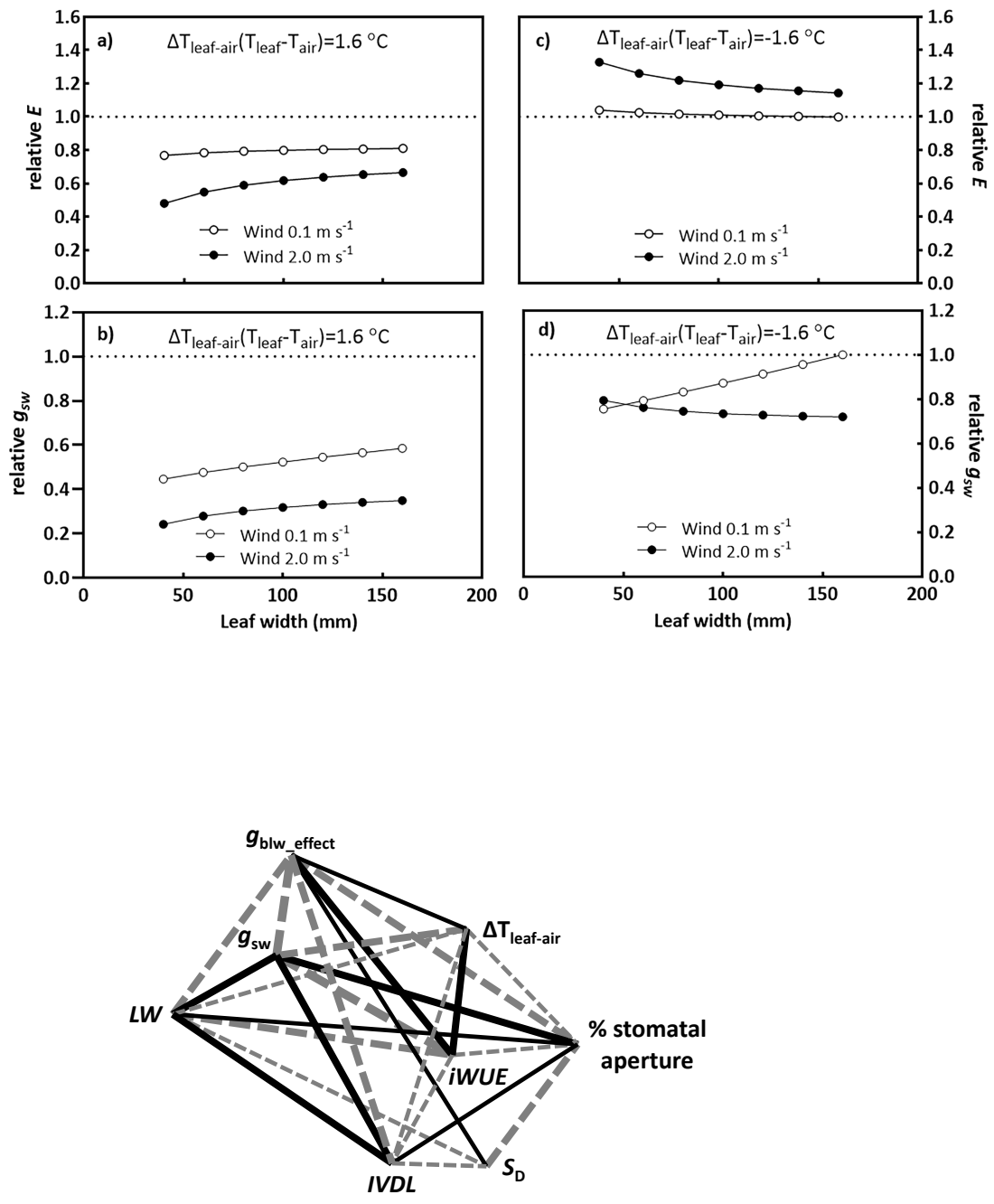


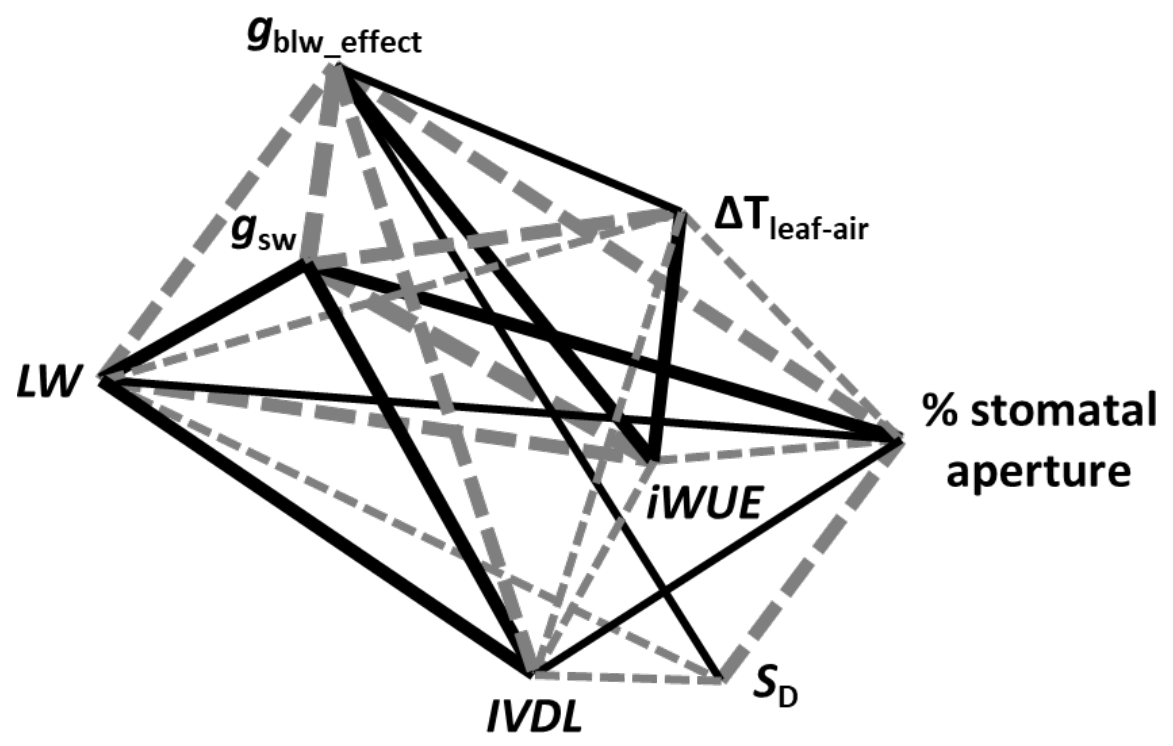

